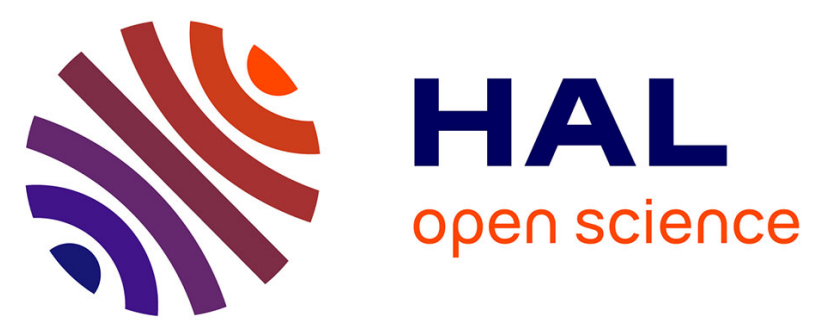

\title{
SAWA experiment? properties of mineral dust aerosol as seen by synergic lidar and sun-photometer measurements
}

\author{
A. E. Kardas, K. M. Markowicz, S. P. Malinowski, G. Karasi?ski, T. \\ Stacewicz, K. Stelmaszczyk, C. Hochhertz, L. Woeste
}

\section{To cite this version:}

A. E. Kardas, K. M. Markowicz, S. P. Malinowski, G. Karasi?ski, T. Stacewicz, et al.. SAWA experiment? properties of mineral dust aerosol as seen by synergic lidar and sun-photometer measurements. Atmospheric Chemistry and Physics Discussions, 2006, 6 (6), pp.12155-12178. hal-00302312

\section{HAL Id: hal-00302312 \\ https://hal.science/hal-00302312}

Submitted on 28 Nov 2006

HAL is a multi-disciplinary open access archive for the deposit and dissemination of scientific research documents, whether they are published or not. The documents may come from teaching and research institutions in France or abroad, or from public or private research centers.
L'archive ouverte pluridisciplinaire HAL, est destinée au dépôt et à la diffusion de documents scientifiques de niveau recherche, publiés ou non, émanant des établissements d'enseignement et de recherche français ou étrangers, des laboratoires publics ou privés. 
SAWA experiment: properties of mineral dust aerosol

\section{SAWA experiment - properties of mineral dust aerosol as seen by synergic lidar and sun-photometer measurements}

A. E. Kardas ${ }^{1}$, K. M. Markowicz ${ }^{1}$, S. P. Malinowski ${ }^{1}$, G. Karasiński ${ }^{2}$, T. Stacewicz ${ }^{2}$, K. Stelmaszczyk ${ }^{3}$, C. Hochhertz ${ }^{3}$, and L. Woeste ${ }^{3}$

${ }^{1}$ Institute of Geophysics, Warsaw University, Poland

${ }^{2}$ Institute of Experimental Physics, Warsaw University, Poland

${ }^{3}$ Free University of Berlin, Germany

Received: 28 September 2006 - Accepted: 20 November 2006 - Published: 28 November 2006

Correspondence to: A. E. Kardas (aekardas@igf.fuw.edu.pl)

A. E. Kardas et al.

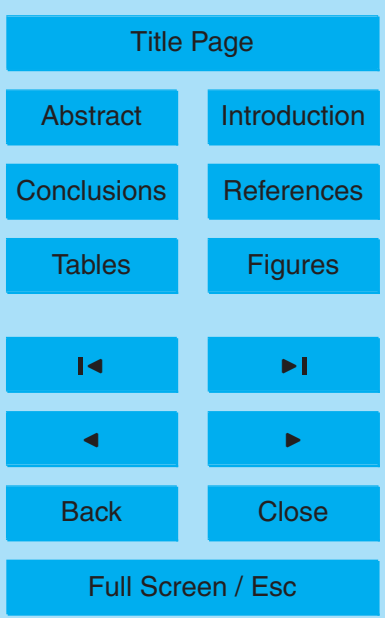

Printer-friendly Version

Interactive Discussion 


\section{Abstract}

We propose a method of retrieving basic information on mineral dust aerosol particles from synergic sun-photometer and multi-wavelength lidar measurements as well as from the observations of lidar light depolarisation. We use this method in a case study 5 of mineral dust episode in Central Europe.

Lidar signals are inversed with a modified Klett-Fernald algorithm. Aerosol optical depth measured with the sun-photometer allows to reduce uncertainties in the inversion procedure through which we estimate vertical profile of aerosol extinction.

Next we assume that aerosol particles may be represented by ensemble of randomly oriented, identical spheroids. Having calculated vertical profiles of aerosol extinction coefficients for lidar wavelengths, we compute the profiles of local Angstrom exponent. We use laser beam depolarisation together with the calculated Angstrom exponents to estimate the shapes (aspect ratios) and sizes of the spheroids. Numerical calculations are performed with the transition matrix (T-matrix) algorithm by M. Mishchenko.

The proposed method was first used during SAWA measurement campaign in Warsaw, spring 2005, to characterise the particles of desert dust, drifting over Poland with a southern-eastern wind (13-14 April). Observations and T-matrix calculations show that mode radii of spheroids representative for desert aerosols' particles are in the range of $0.15-0.3 \mu \mathrm{m}$, while their aspect ratios are lower than 0.7 or larger than 1.7.

\section{Introduction}

It is now commonly known, that aerosols' role in the global climate and its change is important and complex (Houghton, 2001; Satheesh and Krishna Moorthy, 2005). In case of many aerosol types it is not yet established, whether their net contribution to the Earth surface heat balance is positive or negative (Shine and de F. Forster, 1999). One of them is mineral dust (Sokolik and Toon, 1996) emitted from the Earth surface in desert areas and often transported in the atmosphere at long distances. Typical source

SAWA experiment: properties of mineral dust aerosol

A. E. Kardas et al.

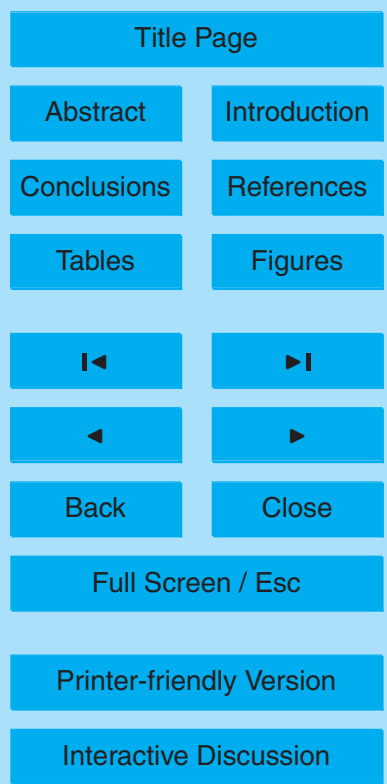

EGU 
areas of dust events observed in Europe are Sahara and Arabian deserts. In this paper we describe investigation of the optical properties of mineral dust transported in the middle atmosphere from these source regions to Poland. Such events are common in Central Europe during the spring time (Borbély-Kiss et al., 2004). We analyse a 5 particular episode of 13-14 April 2005, when a dust plume drifted over Warsaw carried by flow from south and south east. Observations and measurements we describe were performed during SAWA campaign held in spring 2005 at emerging aerosol/radiative transfer laboratory of Warsaw University.

As the campaign was focused on dust events, in order to plan the intensive measure10 ment periods, a long range NAAPS (Navy Aerosol Analysis and Prediction System) was used as a forecast tool. Prediction of a dust plume investigated in this study is presented in Fig. 1.

Among many radiometric instruments used during the campaign were sunphotometers (Microtops and a prototype multi-spectral device Markowicz and Kardas, 15 2006) and the aerosol lidar (Teramobile Profiler from the Free University of Berlin). Microtops measures direct solar radiation in five channels between 380 and $870 \mathrm{~nm}$. Its built-in algorithm produces total Aerosol Optical Depth (AOD) in each channel.

Teramobile Profiler is a multi-wavelength backscattering lidar, originally developed for delivering atmospheric parameters (particle and aerosol density profiles) during experiments on non-linear propagation of ultra-short femtosecond laser pulses in the atmosphere (Rodriguez et al., 2004; Mechain et al., 2005). It is based on a solid-state $10 \mathrm{~Hz} \mathrm{Nd:Yag} \mathrm{laser} \mathrm{(Big} \mathrm{Sky} \mathrm{Laser} \mathrm{CFR} \mathrm{200),} \mathrm{which} \mathrm{delivers} 10$ ns long pulses of energies of $60,50,30$ and $\mathrm{mJ}$, in $1064 \mathrm{~nm}, 532 \mathrm{~nm}$ and $355 \mathrm{~nm}$ wavelengths, respectively. As a receiver the lidar uses F4/200 mm Newtonian telescope. Optical system has a 25 multi-axial design, in which each wavelength is emitted as a separate beam in the vertical direction. The inclination of each beam can be individually adjusted assuring fairly equal overlap with telescope's field-of-view, which compensates the geometrical compression effect (Stelmaszczyk et al., 2005). The backscattered light collected by the telescope is spectrally separated. Its intensity is measured independently at each

SAWA experiment: properties of mineral dust aerosol

A. E. Kardas et al.

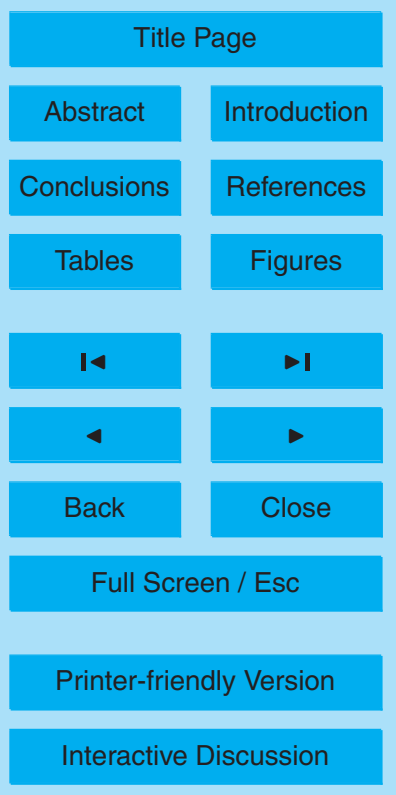

EGU 
wavelength with the photo-multipliers (Hammamatsu R7400 -P04 and -U02 for $355 \mathrm{~nm}$ and $532 \mathrm{~nm}$ ) and with the avalanche photo-diode (EG\&G C30954/5E for $1064 \mathrm{~nm}$ ). All signals are recorded with a 12-bit, $20 \mathrm{MHz}$ transient recorder (Licel) assuring vertical spatial resolution of $7.5 \mathrm{~m}$. Data are then averaged, typically over 1000 laser shots

5 ( $1 \mathrm{~min})$. Intensity of the $532 \mathrm{~nm}$ signal is measured in two polarisations, in directions parallel and perpendicular to the polarisation of the emitted signal. Usually depolarisation of the returned signal is an indicator of non-sphericity of scattering objects, which may help in the evaluation of radiative properties of irregular mineral dust.

In this study we analyse data collected with use of Microtops and Teramobile Profiler 10 taking a special concern in synergy of the measurements. The main idea is to use information on the aerosol optical depth obtained from passive photometer in order to reduce the number of assumptions necessary to invert the lidar signal. Then, with an additional assumption that the particles may be represented by ensemble of randomly oriented, identical spheroids, the size and aspect ratio of the observed aerosol particles are estimated. This assumption allows to adopt the Transition matrix (T-matrix) algorithm by Mishchenko and Travis (1998), in order to calculate scattering properties of the dust.

The paper is organized in the following manner. In the next section details of data processing algorithms and procedures are described. In Sect. 3 results of the measurements are presented and discussed. A short summary and conclusions are given in the last section of the article.

\section{Data processing}

\subsection{Lidar signal inversion method}

The idealised lidar equation can be written after Klett (1981) and Fernald (1984):

${ }_{25} S(z)=\frac{C E}{z^{2}}\left[\beta_{R}(z)+\beta_{A}(z)\right] T_{R}^{2} T_{A}^{2}$.

SAWA experiment: properties of mineral dust aerosol

A. E. Kardas et al.

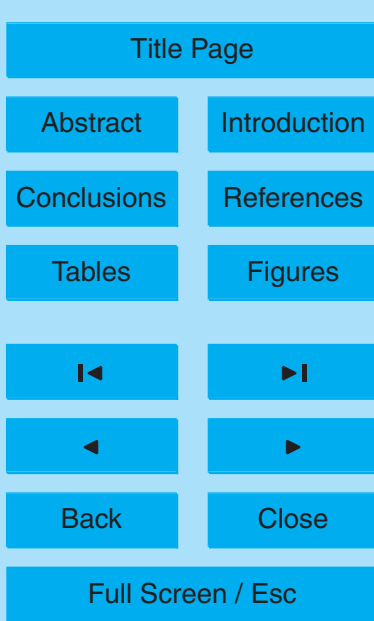

Printer-friendly Version

Interactive Discussion 
Here $S$ is the ideal lidar signal, $z$ is the distance from the lidar (in this case simply height), $C$ - the lidar constant, $E$ - the laser impulse energy, $\beta_{R}$ and $\beta_{A}$-backscatter coefficients for molecules and aerosol particles, $T_{R}$ and $T_{A}$ - the molecular and aerosol trasmittances.

$5 \quad$ Solving Eq. (1) requires introducing a new variable:

$P(z)=\frac{S(z)}{E} z^{2}$,

and assuming a relationship between aerosol's backscatter and extinction coefficient $\left(a_{A}\right)$ (Fernald, 1984):

$\beta_{A}(z)=R_{A}(z) a_{A}(z)$.

$6,12155-12178,2006$

\section{SAWA experiment:} properties of mineral dust aerosol

A. E. Kardas et al.

10 The $R_{A}$ coefficient is called the lidar ratio.

Equation (3) allows to calculate the unknown value of the aerosol transmittance in Eq. (1), as:

$T_{A}=\exp \left(-\int a(z) d z\right)=\exp \left(-\int \frac{\beta_{A}(z)}{R_{A}(z)} d z\right)$.

In order to estimate this integral usually a simplifying assumption that $R_{A}$ is independent of $z$ is adopted (Landulfo et al., 2003; Iwasaka et al., 2003; Welton et al., 2000). Then the solution of Eq. (1) may be written in the following form:

$\beta_{A}(z)=\frac{P(z) T_{R}^{2(r-1)}(z)}{C-\frac{2}{R_{A}} \int_{0}^{z} P\left(z^{\prime}\right) T_{R}^{2(r-1)}\left(z^{\prime}\right) d z^{\prime}}-\beta_{R}(z)$,

where

$r=\frac{R_{R}}{R_{A}}$

and $R_{R}=3 / 8 \pi$ is the backscatter to extinction ratio in Rayleigh scattering. 
Calculations with the modified Klett-Fernald algorithm begin at the top of the measurement range, assuming $\beta_{A}\left(z_{\max }\right)=0$. Then pairs of equations similar to Eq. (5), written for subsequent levels in the atmosphere, " $z$ " and " $z-d z$ " are solved. This allows to avoid the necessity of establishing the value of the lidar constant $C$ (Welton et al., 5 2000). $\beta_{R}(z)$ is usually calculated with empirical equations for assumed or measured vertical profiles of temperature and pressure in the atmosphere.

Nevertheless there is still one unknown remaining: $R_{A}$. In order to evaluate it we propose the following iterative procedure. In the first step we assume $R_{A}=1$ or $R_{A}=R_{R}$. Then, after calculating the whole vertical profile of $\beta_{A}, R_{A}$ is redefined as:

${ }_{10} R_{A}=\frac{\int \beta_{A}(z) d z}{\tau_{S P}}$

where $\tau_{S P}$ is the total optical depth of aerosol, measured with the sun-photometer (Welton et al., 2000). The calculations begin again at the top of the range and the procedure is repeated until the difference between subsequent values of $R_{A}$ is sufficiently small. With this additional bond the common practise (Landulfo et al., 2003; Iwasaka et al., 15 2003) of guessing $R_{A}$ 's value is avoided.

The next improvement of the procedure comes from the following observation. When several aerosol layers are present in the atmosphere, it is advisable to allow for $R_{A}$ to differ between them. Therefore it is desirable to divide the atmosphere into appropriate layers determined on the basis of the lidar backscatter signal. More details on the particular division adopted in the case study can be found in Sect. 3.2. Here we briefly describe the way, in which the improvement can be adopted. In first step extinction coefficient profiles should be calculated for the whole atmosphere. Then, integration within the chosen height ranges should give optical depth values to be used instead $\tau_{S P}$ while running the algorithm for each layer separately.

\section{ACPD}

6, 12155-12178, 2006

SAWA experiment: properties of mineral dust aerosol

A. E. Kardas et al.

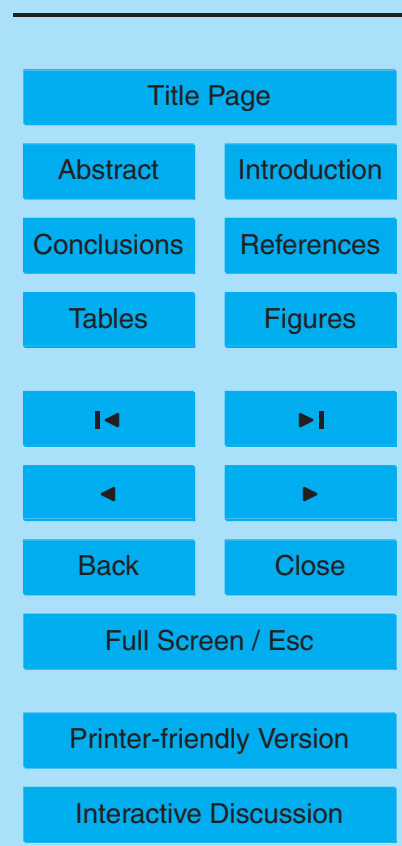




\subsection{Numerical calculations (T-matrix)}

One of the goals of the SAWA campaign was to find a mathematical representation of the dust particles, suitable for a radiative transfer model. This required the possibility of evaluating the properties of particles on the basis of measured values. We decided to 5 use the transition matrix (T-matrix) method, initially developed by Waterman (1971) and implemented by Mishchenko and Travis (1998), consisting basically on the numerical solution of Maxwell's equations.

Electric field of the incident $\left(E^{i}\right)$ and scattered by a single particle radiation $\left(E^{s}\right)$ is expanded in vector spherical functions $M_{m n}$ and $N_{m n}$ (Tsang et al., 1985):

${ }_{10} \quad E^{i}(\boldsymbol{R})=\sum_{n=1}^{n_{\max }} \sum_{m=-n}^{n}\left[a_{m n} \boldsymbol{R} g M_{m n}(\boldsymbol{R})+b_{m n} \boldsymbol{R} g N_{m n}(\boldsymbol{R})\right]$

$E^{S}(R)=\sum_{n=1}^{n_{\max }} \sum_{m=-n}^{n}\left[p_{m n} M_{m n}(R)+q_{m n} N_{m n}(R)\right]$.

Here the origin of the coordinate system is assumed to be inside the particle, $\boldsymbol{R}$ is the vector of position (larger than the radius of a scattering particle's circumscribing sphere), $g$ - the asymmetry parameter, $a_{m n}, b_{m n}, p_{m n}$ and $q_{m n}$ - coefficients.

As the Maxwell's equations and boundary conditions are linear, the relationship between coefficients for scattered and incident light may be represented by a transition matrix (T) (Mishchenko and Travis, 1998):

$[p, q]=\mathbf{T}[a, b]$.

The elements of a T-matrix depend only on the physical characteristics of the particle, such as size, shape, refractive index and orientation. Therefore once calculated, a Tmatrix can be used in computations for any directions of beam incidence or scattering. Furthermore this approach is also useful in modelling the interaction between light and an ensemble of randomly oriented particles.

\section{ACPD}

6, 12155-12178, 2006

SAWA experiment: properties of mineral dust aerosol

A. E. Kardas et al.

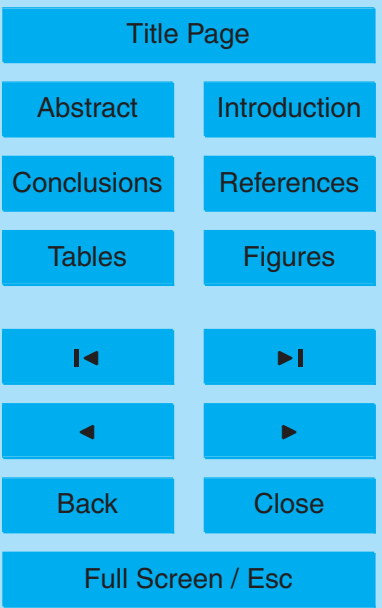

Printer-friendly Version

Interactive Discussion 
The standard procedure for calculating the transition matrix for a non-spherical particle uses the extension of the particle's internal filed extended in vector spherical functions analogically to Eqs. (8) and (9) (Waterman, 1971). The T-matrix may be calculated for particles of arbitrary shapes, but the formulas simplify decidedly, while a rotational 5 symmetry is assumed.

We assume that the observed dust particles can be represented by an ensemble of randomly oriented spheroids with a log-normal size distribution and fixed aspect ratios. This allows us to create look-up tables for evaluating particles' parameters on the basis of the lidar and the sun-photometer retrievals (Sects. 2.3 and 2.4).

10 The necessary numerical calculations were performed with the use of the T-matrix FORTRAN routine (Mishchenko and Travis, 1998) available on http://www.giss.nasa. gov/ crmim/t_matrix.html.

\subsection{Determination of particles' size}

We decided to estimate the mean size of the particles, using the values of the Angstrom 15 exponent $(\alpha)$, retrieved from the profiles of extinction coefficient at different wavelengths. T- matrix code was used to perform numerical simulations of the light transfer through an ensemble of particles mentioned in Sect. 2.2. $532 \mathrm{~nm}$ wavelength and the refractive index of sand, equal to $1.53+0.008$ i were assumed.

Results of calculations for a number of different mode radii show, that at least within 20 radius is monotonic and shape-independent. This can be observed in Fig. 2, where the plots corresponding to different spheroids' aspect ratios overlap. Aspect ratio 2 means oblate spheroids, 0.5 - prolate, 1 - spheres.

Reading Fig. 2 is useful in order to estimate the mode radius of spheroids represen25

\section{ACPD}

6, 12155-12178, 2006

SAWA experiment: properties of mineral dust aerosol

A. E. Kardas et al.

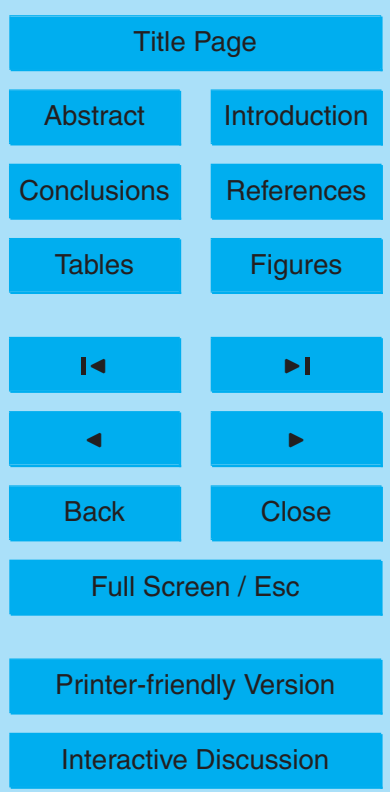


A parameter which is highly sensible to particles' shape is the depolarisation of the returning lidar signal, defined as:

$\delta=P_{R} / P_{L}$.

5 Here $P_{R}$ and $P_{L}$ are the values of lidar returns with polarisations perpendicular and parallel to the polarisation of the original beam (Stephens, 1994).

T-matrix simulations performed for different mode radii of aerosol particles (Fig. 3) show, that $\delta$ can be used in estimating the aspect ratio of aerosol particles for single scattering approach, as it always equals zero for spheres and is decidedly higher for spheroids. Unfortunately the result is not unequivocal - there are at least two possible aspect ratios for given size and each non-zero depolarisation.

\section{Experimental results}

\subsection{SAWA measurement campaign}

As mentioned, SAWA experiment took place in April and May 2005, in Warsaw. Its 15 main goal was to examine the aerosols typical for the desert dust episodes in Central Europe. During the campaign one major event of this kind appeared, between 12 and 19 April. Synergic lidar and sun-photometer measurements were made on 13 and 14 April. Unfortunately, as it was noticed later, the UV channel of the Teramobile Profiler was not operating correctly and its records were not accounted in the analysis.

$20 \quad$ Figure 4 presents lidar returns in wavelength $532 \mathrm{~nm}$, collected on 13 and 14 April. In the atmospheric boundary layer between the surface and the level of approximately $1.5 \mathrm{~km}$ one may observe large concentrations of presumably urban aerosols (strong lidar signals). Higher, up to $4-5 \mathrm{~km}$, the relatively wide layer of increased returns, likely due to the enhanced aerosol concentration, is clearly visible (grey). Its presence is

SAWA experiment: properties of mineral dust aerosol

A. E. Kardas et al.

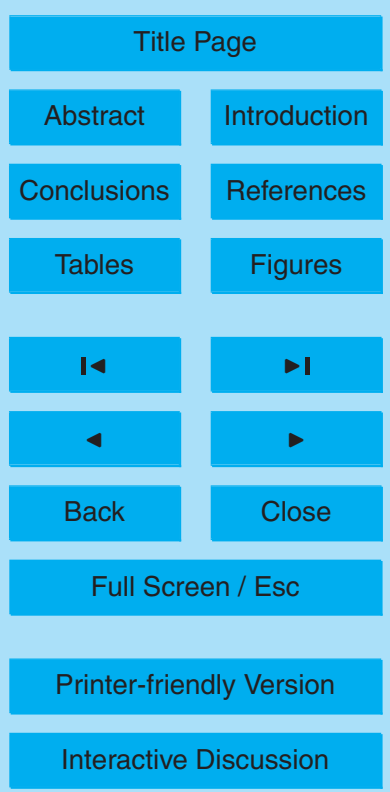


in agreement with the prediction of NAAPS model presented in Fig. 1, which shows a dust plume transported in the middle troposphere from the regions of Sahara and Arabian Desert.

\subsection{Measured AODs and aerosol extinction profiles}

5 During SAWA experiment total aerosol optical depths were measured with Microtops sun-photometer. As the instrument measures direct solar radiation, it can only be used during day time and when the sun's disc is not obscured by clouds. This means, that there are gaps in the Microtops measurement series, especially during the night time. In these gaps values of AOD were linearly interpolated between measurement times.

AODs measured during the dust episode (Fig. 5) were noticeably higher than those observed on other days. For example on the 14 April (Fig. 5b) the optical depth in $500 \mathrm{~nm}$ wavelength reached 0.67 in contrast to values of $0.05-0.25$ characteristic for days without the drifting dust in the middle troposphere.

Since Microtops channels do not agree with the lidar ones, in order to estimate AODs in the lidar wavelengths Microtops measurements had to be transformed with the use of the Angstrom power law (Angstrom, 1964). In the adopted procedure atmosphere was divided into three layers: boundary layer (urban aerosols), desert dust and "clear" air (Fig. 6). The first border discriminating between the boundary layer and the desert dust layer in the troposphere was assumed between 1 and $1.5 \mathrm{~km}$ heights, at the level of the local minimum of the lidar return signal. The upper border of the mineral aerosol layer was set between $4.95 \mathrm{~km}$ and $5.6 \mathrm{~km}$, at the level of minimum depolarisation of the lidar signal (Fig. 7).

Estimates based on the preliminary application of Klett algorithm (considering atmosphere as a single layer) show that the optical thickness of mineral dust was comparable to that of the boundary layer aerosol - see Fig. 8. When consulting the figure notice, that in the night time, when we did not have reliable measurements of AODs and linear interpolation of Microtops measurements filled the gap in the data, the adopted procedure is less reliable than during the day.

SAWA experiment: properties of mineral dust aerosol

A. E. Kardas et al.

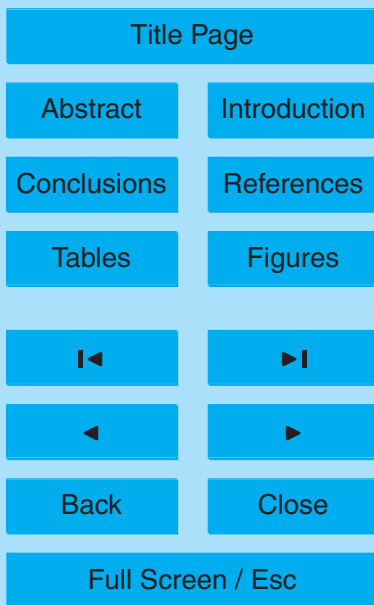

Printer-friendly Version

Interactive Discussion 
From the lidar signals at 532 and $1064 \mathrm{~nm}$ profiles of extinction coefficients were derived, following the procedure described in Sect. 2.2. Figure 9 shows result for $532 \mathrm{~nm}$ wavelength. Extinction coefficients in the desert dust layer are in the range of $0.5 \times 10^{-4} \mathrm{~m}^{-1}$ to $1.5 \times 10^{-4} \mathrm{~m}^{-1}$. They are lower than the values observed for the 5 urban aerosols, but as the dust layer is relatively thick its influence on radiative flux is important.

\subsection{Estimations of particles' sizes and shapes}

Figure 10 shows vertical profiles of the local Angstrom exponent computed from the extinction coefficients for $532 \mathrm{~nm}$ and $1064 \mathrm{~nm}$ wavelengths. Values in the lowest layer 10 (consult Fig. 6) are between 0.5 and 1.5, which corresponds to the particles of radii in the range $0.25-0.35 \mu \mathrm{m}$ (see Fig. 2). In the middle layer (with the desert dust aerosol), Angstrom exponents are in the range of $0.7-2.5$, which corresponds to the particles of radii in the range $0.15-0.3 \mu \mathrm{m}$.

Figure 7, already mentioned in Sect. 3.2, presents signal depolarisation calculated for the $532 \mathrm{~nm}$ wavelength. Comparing the depolarisation in the lowest layer and in the middle layer with desert aerosol we see, that mineral dust of depolarisation larger than 0.1 differs decidedly from the aerosol in the boundary layer whose depolarisation is close to zero. As Fig. 3 indicates, such level of depolarisation means that the aspect ratios of spheroids representative for mineral dust are more than 1.7 in the case of oblate spheroids or less than 0.7 in the case of prolate spheroids.

\section{Conclusions}

A dust episode observed on 13 and 14 April 2005 during SAWA campaign held in Warsaw is analysed. Synergic measurements by the means of multi-wavelength lidar and Microtops sun-photometer allow to reduce the number of assumptions needed to retrieve profiles of extinction coefficients. These profiles together with an additional

\section{ACPD}

6, 12155-12178, 2006

SAWA experiment: properties of mineral dust aerosol

A. E. Kardas et al.

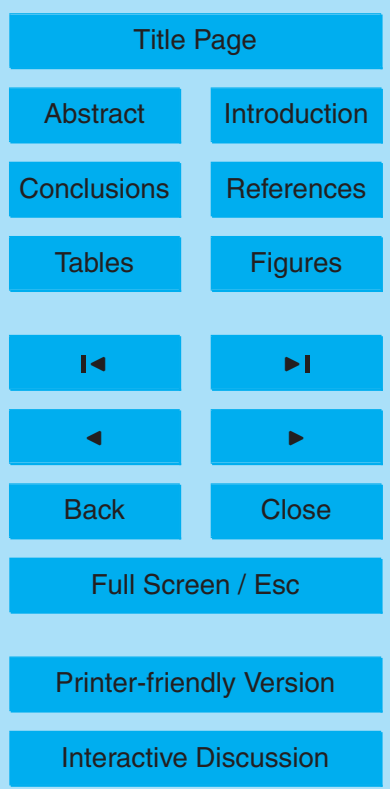


information on the depolarisation of the lidar signal and assumption of the spheroidal shape of aerosol particles, were used in numerical calculations performed using the T-matrix code. As the result we estimated sizes and shapes (aspect ratios) of the observed mineral dust particles.

5 The mode radii of these particles is in the range of $0.15-0.3 \mu \mathrm{m}$. This is consistent with the values commonly used in modelling radiative processes for aerosol type "mineral transported" (Hess et al., 1998). The aspect ratios of spheroids representative for the observed mineral dust are smaller than 0.7 or larger than 1.7. This result is important, since recent studies indicate that non-sphericity of the particles may cause up to $10 \%$ positive or negative change in the aerosol forcing (Markowicz et al., 2005).

The retrieved information of the size and shape of the mineral dust particles transported on the long distances from Sahara and Arabian deserts will be used in the new radiative model of dust.

Acknowledgements. This research was supported by 2 P04D 06927 research grant from Polish 15 Ministry of Education and Science. Some activities related to this research were supported by the European Commission Fifth Framework Program's Project EVK2-CT2002-80010-CESSAR. We thank to all graduate students, in particular to M. Witek and M. Posyniak for their help with the SAWA measurement campaign.

\section{References}

20 Angstrom, A.: The parameters of atmospheric turbidity, Tellus, 16, 64-75, 1964. 12164

Borbély-Kiss, I., Kiss, Á.Z., Koltay, E., Szabó, G., and Bozó, L.: Saharan dust episodes in Hungarian aerosol: Elemental signatures and transport trajectories, J. Aerosol Sci., 35, 12051224, 2004. 12157

Fernald, F. G.: Analysis of atmospheric lidar observations: some comments, Appl. Opt., 23, 652-653, 1984. 12158, 12159

Hess, M., Kopepke, P., and Schult, I.: Optical Properties of Aerosol and Clouds: The Software Package OPAC, Bull. Am. Meteorol. Soc., 79, 831-844, 1998. 12166

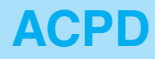

6, 12155-12178, 2006

SAWA experiment: properties of mineral dust aerosol

A. E. Kardas et al.

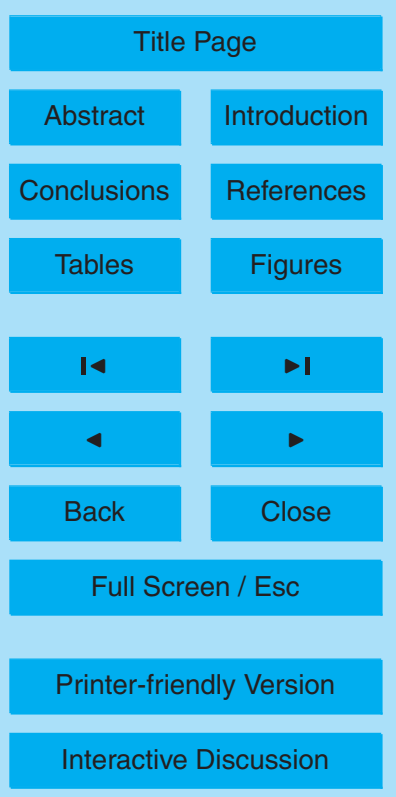


Houghton, J. T.: Climate change 2001: the scientific basis: contribution of Working Group I to the third asessement report of the Intergovernemental Panel on Climate Change, Cambridge University Press, Cambridge, UK, New York, 2001. 12156

Iwasaka, Y., Shibata, T., Nagatani, T., Shi, G.-Y., Kim, Y. S., Matsuki, A., Trochkine, D., Zhang, $5 \quad$ D., Yamada, M., Nagatani, M., Nakata, H., Shen, Z., Li, G., Chen, B., and Kawahira, K.: Large depolarization ratio of free tropospheric aerosols over the Taklamakan Desert revealed by lidar measurements: Possible diffusion and transport of dust particles, J. Geophys. Res., 108, ACE 20-1-8, 2003. 12159, 12160

Klett, J. D.: Stable analytical inversion solution for processing lidar returns, Appl. Opt., 20, 211-220, 1981. 12158

Landulfo, E., Papayannis, A., Artaxo, P., Castanho, A. D. A., De Freitas, A. Z., Souza, R. F., Vieira Junior, N. D., Jorge, M. P., Sanchez-Ccoyllo, O. R., and Moreira, D. S.: Synergetic measurements of aerosol over Sao Paulo, Brazil, using LIDAR, sunphotometer and satellite data during the dry season, Atmos. Chem. Phys., 3, 1523-1539, 2003. 12159, 12160

Markowicz, K.M., Kardas, A.E., Hochherz, C., Stelmaszczyk, K., Rozwadowska, A., Zielinski, T., Karasinski, G., Remiszewska, J., Witek, M., Malinowski, S. P., Stacewicz, T., and Woeste, L.: Observation of aerosol properties and radiative forcing of nonspherical particles over Poland, ACCENT symposium, Urbino, 2005. 12166

Markowicz, K. M. and Kardas, A. E.: Retrieval of aerosol optical properties and estimation of aerosol forcing based on multi-spectral sun-photometer observations. 12th Conference on Cloud Physics (Madison, WI, USA, 09-14 July 2006), available at http://ams.confex.com, 2006. 12157

Mechain, G., Mejean, G., Ackermann, R., Rohwetter, P., Andre, Y.-B., Kasparian, J., Prade, B., Stelmaszczyk, K., Yu, J., Salmon, E., Winn, W., Schlie, L. A., Mysyrowicz, A., Sauerbrey, R., Woeste, L., and Wolf, J.-P.: Propagation of fs TW laser filaments in adverse atmospheric conditions, Appl. Phys. B, 80, 785-789, 2005. 12157

Mishchenko, M. I. and Travis, L. D.: Capabilities and limitations of a current FORTRAN implementation of the T-matrix method for randomly oriented rotationally symmetric scatterers, J. Quant. Spectrosc. Radiat. Transfer, 60, 309-324, 1998. 12158, 12161, 12162

30 Rodriguez, M., Bourayou, R., Mejean, G., Kasparian, J., Yu, J., Salmon, E., Scholz, A., Stecklum, B., Eisloffel, J., Laux, U., Hatzes, A. P., Sauerbrey, R., Woeste, L., and Wolf, J.-P.: Kilometer-range non-linear propagation of femtosecond laser pulses, Phys. REV. E, 69, 036607-1-036607-7, 2004. 12157

SAWA experiment: properties of mineral dust aerosol

A. E. Kardas et al.

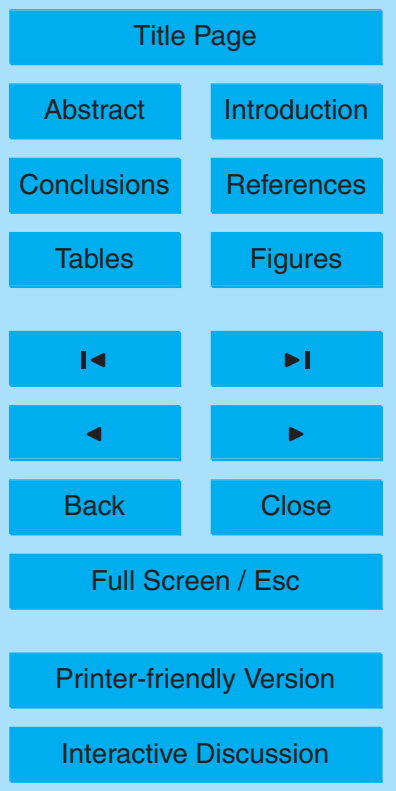


Satheesh, S. K. and Krishna Moorthy, K.: Radiative effects of natural aerosols: a review, Atmos. Environ., 39, 2089-2110, 2005. 12156

Shine, K. P. and Forster, P. M. D. F.: The effect of human activity on radiative forcing of climate change: a review of recent developments, Glob. Planet. Change, 20, 205-225, 1999. 12156

5 Sokolik, I. N. and Toon, O. B.: Direct radiative forcing by airborne mineral aerosols, J. Aerosol Sci., 27, S11-S12, 1996. 12156

Stelmaszczyk, K., Dell'Aglio, M., Chudzynski, S., Stacewicz T., and Woeste, L.: Analytical function for lidar geometrical compression form-factor calculations, Appl. Opt., 44, 13231331, 2005. 12157

10 Stephens, D. L.: Remote Sensing of the Lower Atmosphere, University Press, New York, 1994. 12163

Tsang, L., Kong, J. A., and Shin, T. Y.: Theory of Microwave Remote Sensing, Wiley, New York, 1985. 12161

Waterman, P. C.: Symmetry, Unitarity, and Geometry in Electromagnetic Scattering, Phys. Rev. $15 \quad$ D., 3, 825-839, 1971. 12161, 12162

Welton, E. J., Voss, K. J., Gordon, H. R., Maring, H., Smirnov, A., Holben, B., Schmidt, B., Livingston, J. M., Russel, P. B., Durkee, P. A., Formenti, P., and Andreae, M. O.: Groundbased lidar measurements of aerosols during ACE-2: instrument description, results and comparisons with other ground-based and airborne measurements, Tellus, 52B, 636-651,

\section{SAWA experiment: properties of mineral dust aerosol}

A. E. Kardas et al.

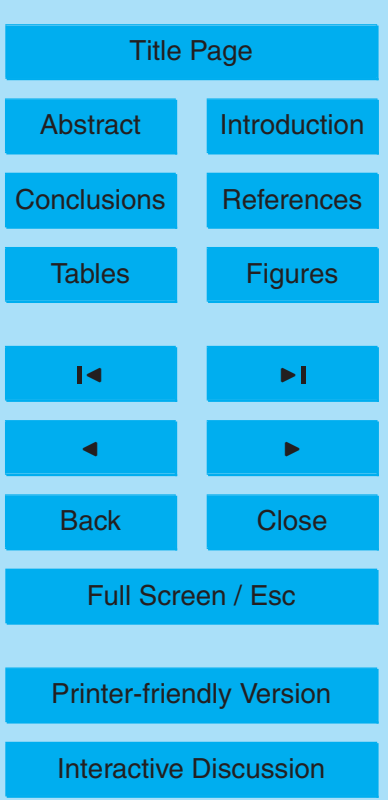




\section{ACPD}

6, 12155-12178, 2006

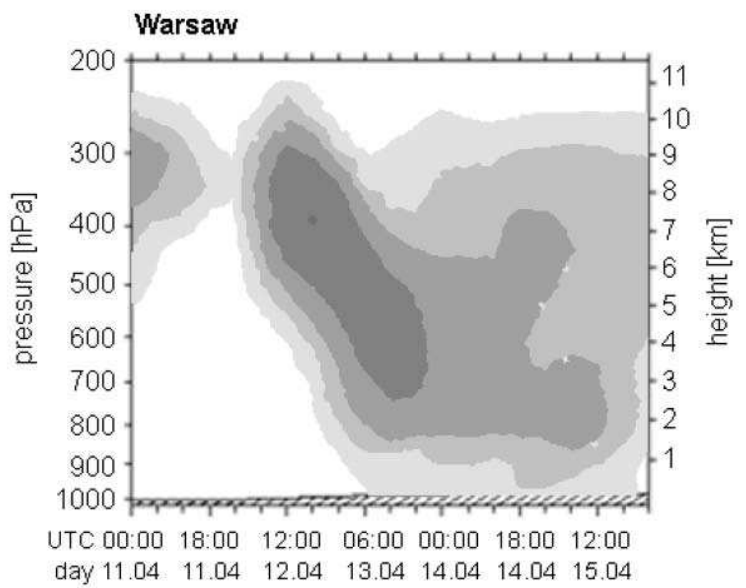

\section{SAWA experiment: properties of mineral dust aerosol}

A. E. Kardas et al.

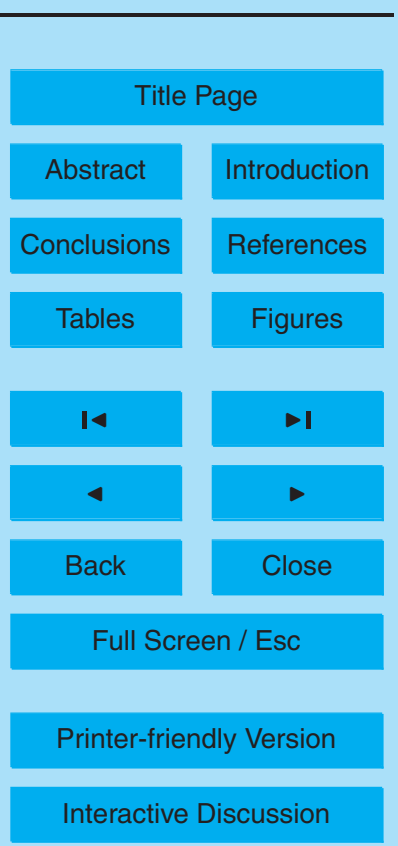

Fig. 1. Dust concentration forecast over Warsaw taken from the NAAPS model, NRL Monterey Aerosol Page (http://www.nrlmry.navy.mil/aerosol/). The largest concentrations of dust were forecasted on 12-13 April 2005, above $3 \mathrm{~km}$ level. 


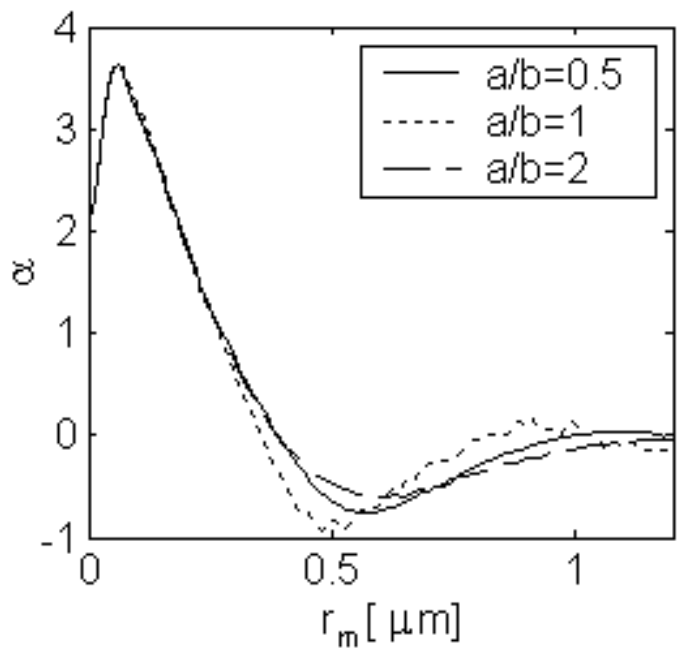

$6,12155-12178,2006$

\section{SAWA experiment: properties of mineral dust aerosol}

A. E. Kardas et al.

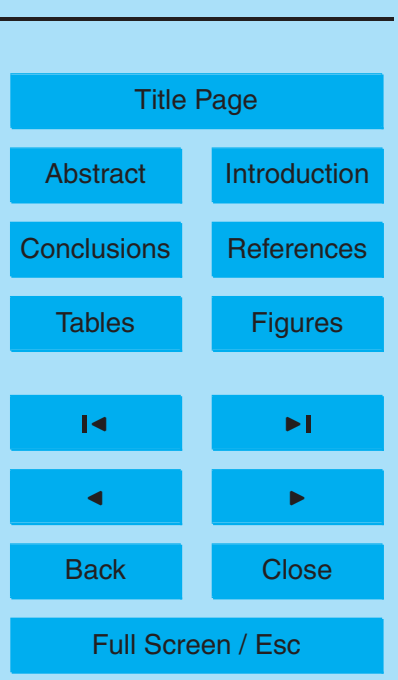

Fig. 2. Angstrom exponent's $(\alpha)$ dependency of the mode radius $\left(r_{m}\right)$ of randomly oriented spheroids with a log-normal size distribution, calculated for the refractive index of sand and various aspect ratios $(\mathrm{a} / \mathrm{b})$. In the radii range of $0.1-0.6 \mu \mathrm{m}$, the relationship between $\alpha$ and the mean radius is monotonic and shape-independent. 


\section{ACPD}

$6,12155-12178,2006$

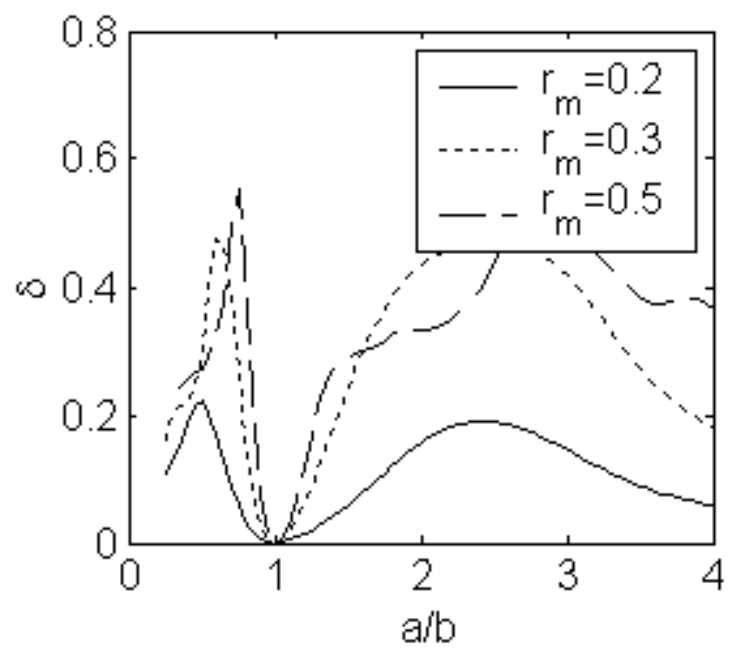

SAWA experiment: properties of mineral dust aerosol

A. E. Kardas et al.

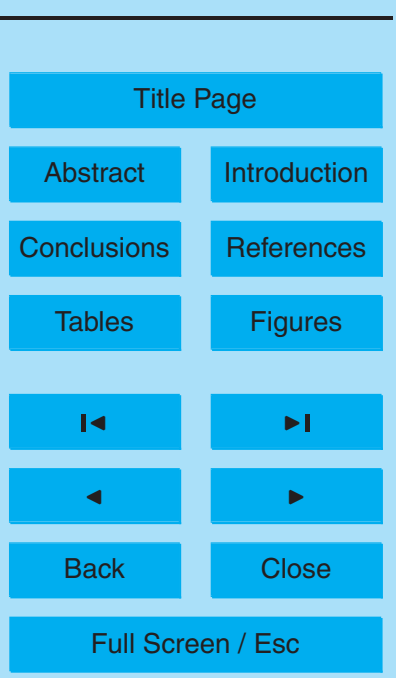

Fig. 3. Depolarisation's $(\delta)$ dependency of the aspect ratio $(\mathrm{a} / \mathrm{b})$ of randomly oriented spheroids with a log-normal size distribution, calculated for the refractive index of sand and different mode radii $\left(r_{m}[\mu \mathrm{m}]\right)$. The value always reaches 0 for spherical particles $(a / b=1)$. 


\section{ACPD}

$6,12155-12178,2006$

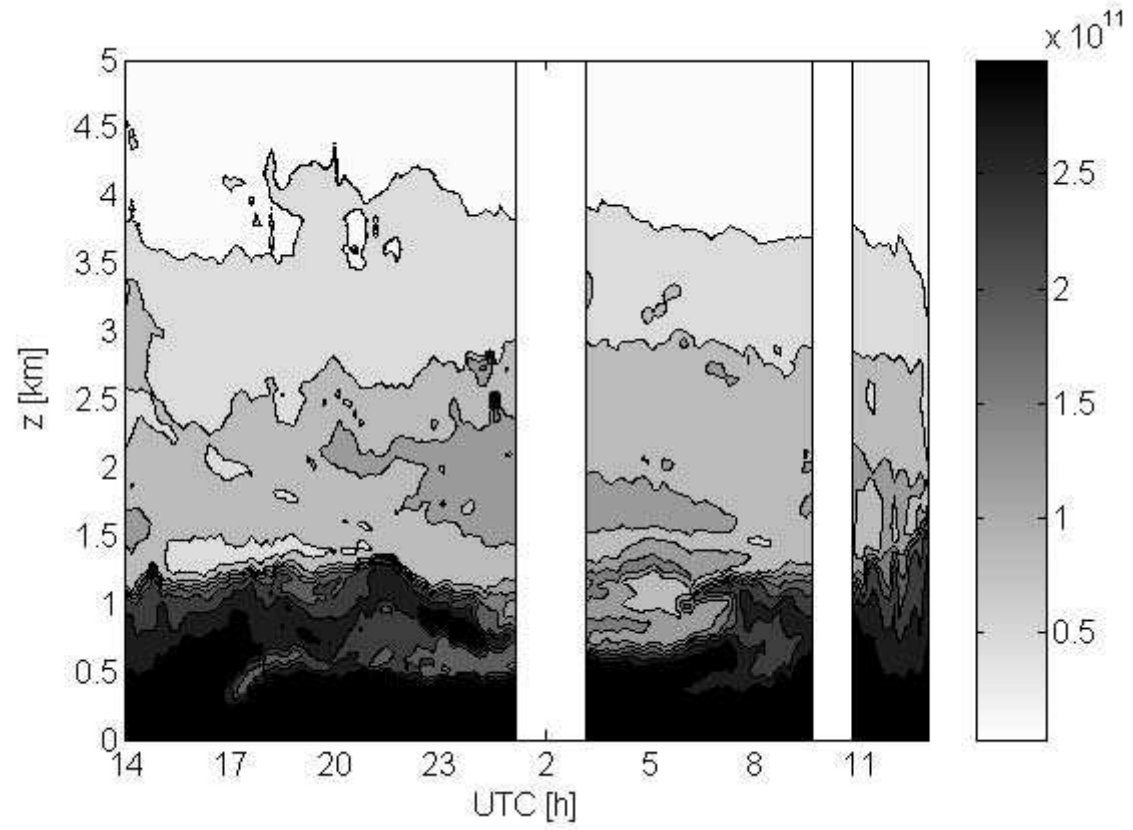

SAWA experiment: properties of mineral dust aerosol

A. E. Kardas et al.

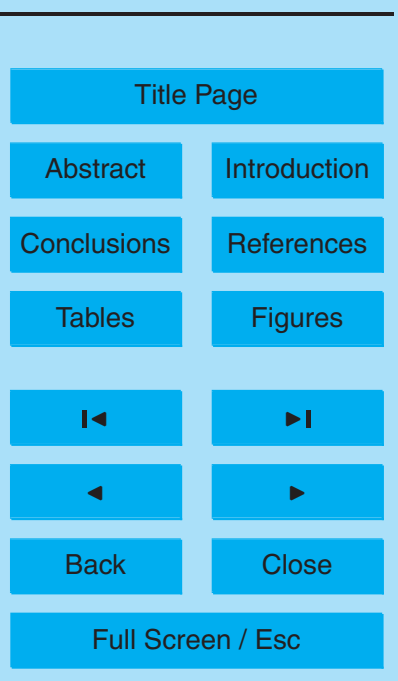

Fig. 4. Temporal evolution of lidar returns recorded for $532 \mathrm{~nm}$ wavelength on 13-14 April 2005 in Warsaw (arbitrary units). Light and moderate grey areas located between 1.2 and $4 \mathrm{~km}$ correspond to the mineral dust layer.

Printer-friendly Version

Interactive Discussion 


\section{ACPD}

$6,12155-12178,2006$
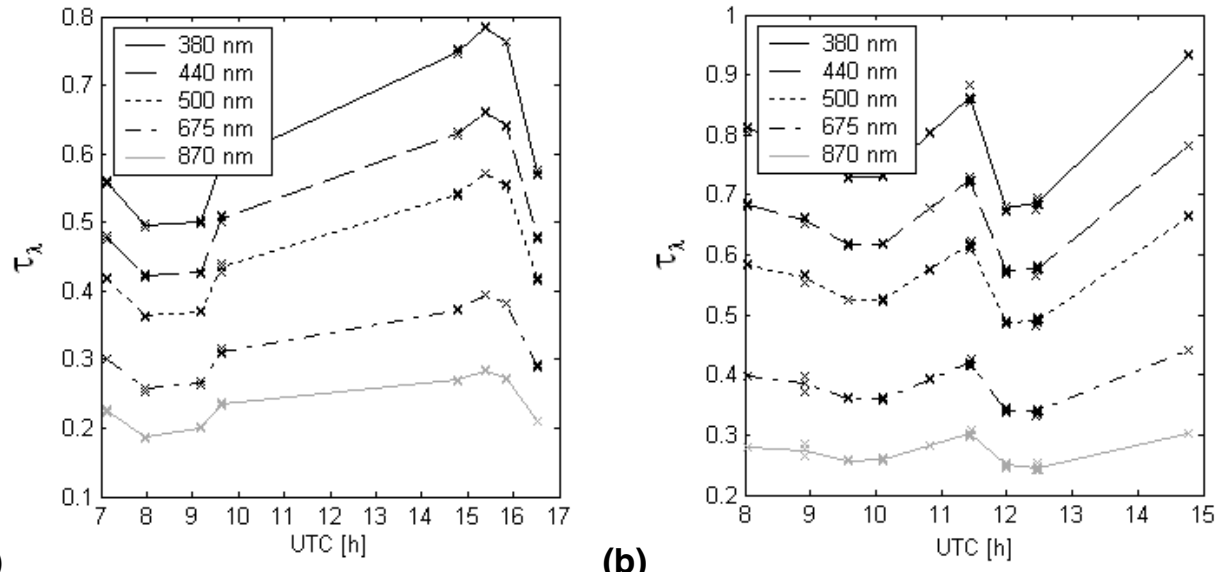

SAWA experiment: properties of mineral dust aerosol

A. E. Kardas et al.

(a)

(b)

Fig. 5. Temporal evolution of aerosol optical depth (AOD) measured with Microtops on the 13 (a) and 14 (b) April 2005 in Warsaw.

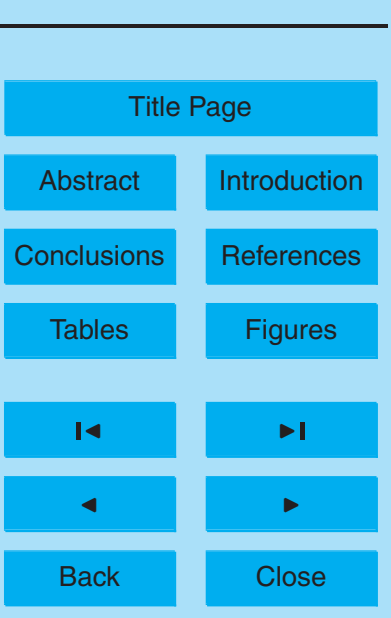

Full Screen / Esc

Printer-friendly Version 


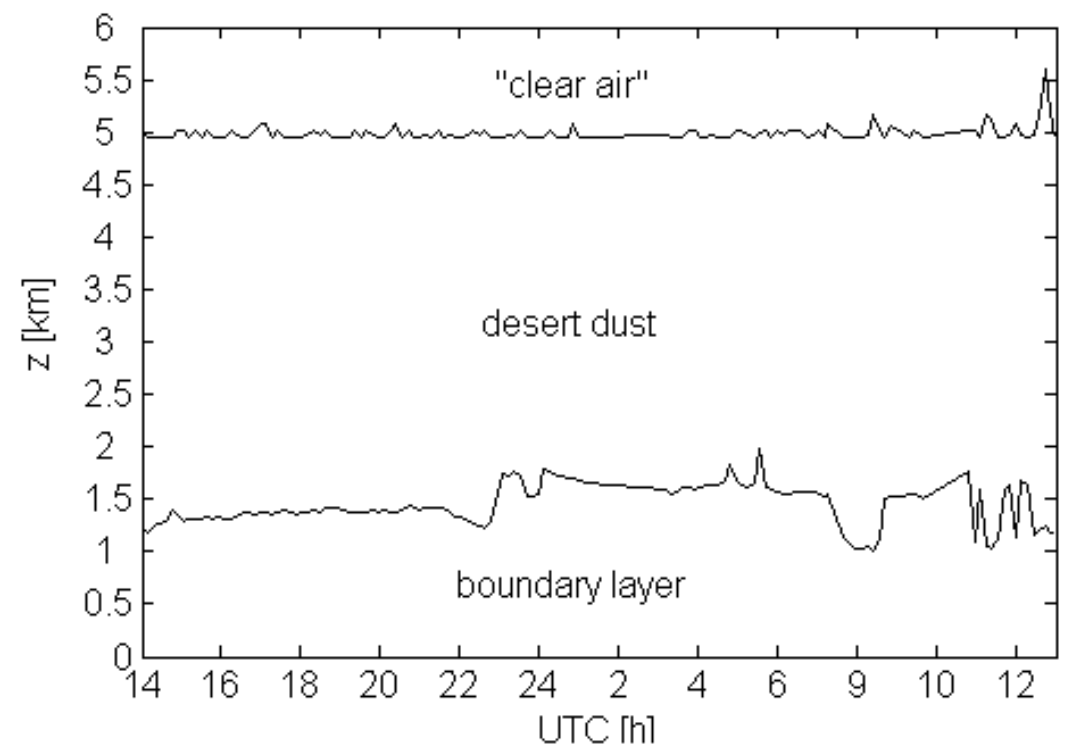

\section{SAWA experiment: properties of mineral dust aerosol}

A. E. Kardas et al.

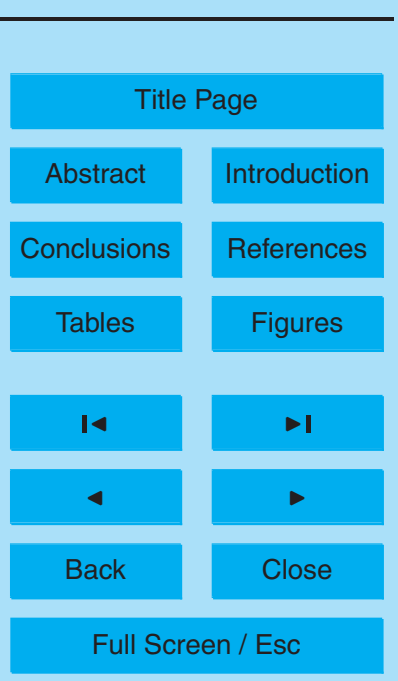
desert dust layer and the clear air layer. 


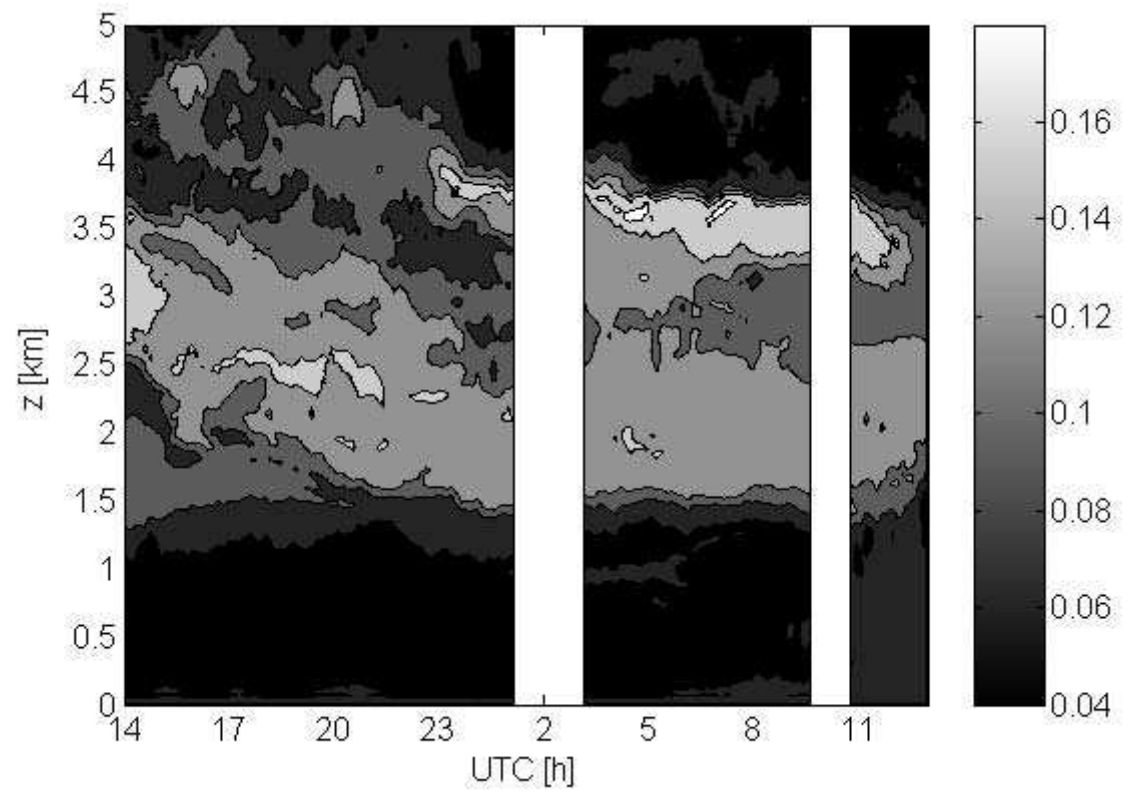

$6,12155-12178,2006$

\section{SAWA experiment: properties of mineral dust aerosol}

A. E. Kardas et al.

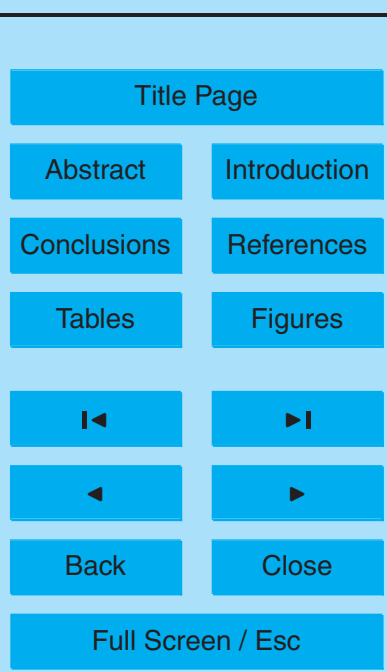

Fig. 7. Temporal evolution of light depolarisation profile measured by lidar at $532 \mathrm{~nm}$ wavelength, 13-14 April 2005, Warsaw. Relatively high depolarisation values (grey layer between 1.2 and $4 \mathrm{~km}$ ) correspond to mineral dust. 


\section{ACPD}

$6,12155-12178,2006$

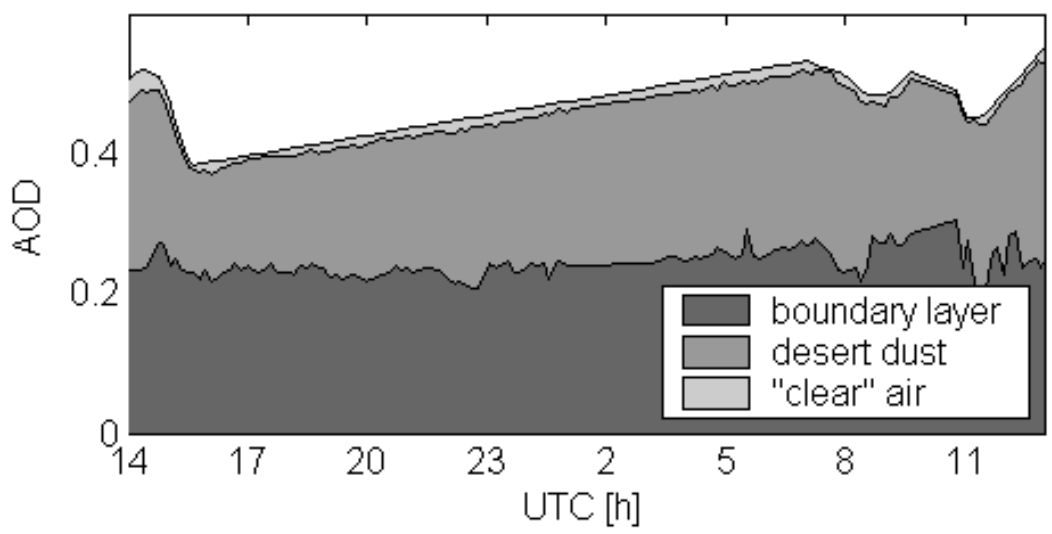

SAWA experiment: properties of mineral dust aerosol

A. E. Kardas et al.

Title Page

Abstract

Introduction

Conclusions

References

Tables

Figures

14

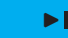

Fig. 8. Temporal evolution of aerosol optical depths (AOD) of atmospheric layers estimated on the basis of Microtops and lidar measurements on the 13-14 April 2005 in Warsaw $(532 \mathrm{~nm}$ wavelength). Total AODs are linearly interpolated between measurement times.

4

Back

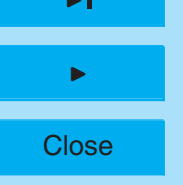

Full Screen / Esc

Printer-friendly Version

Interactive Discussion 


\section{ACPD}

$6,12155-12178,2006$

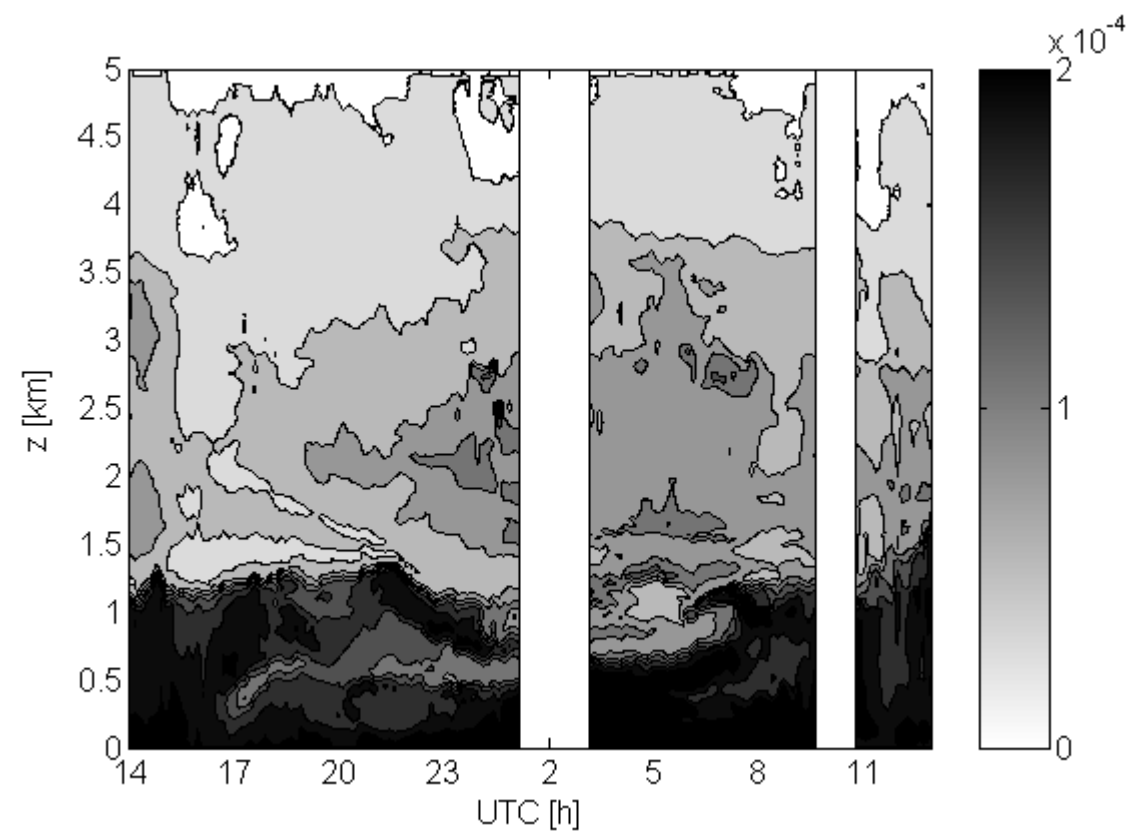

SAWA experiment: properties of mineral dust aerosol

A. E. Kardas et al.

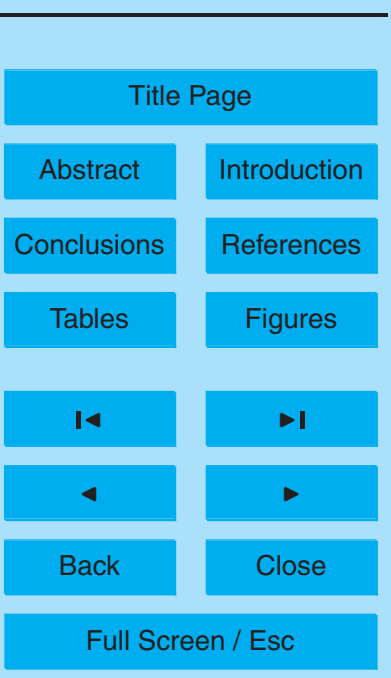

Fig. 9. Temporal evolution of aerosol extinction coefficient $[1 / \mathrm{m}]$ vertical profiles retrieved from lidar returns for the wavelength $532 \mathrm{~nm}$ on 13-14 April 2005.

Printer-friendly Version

Interactive Discussion 


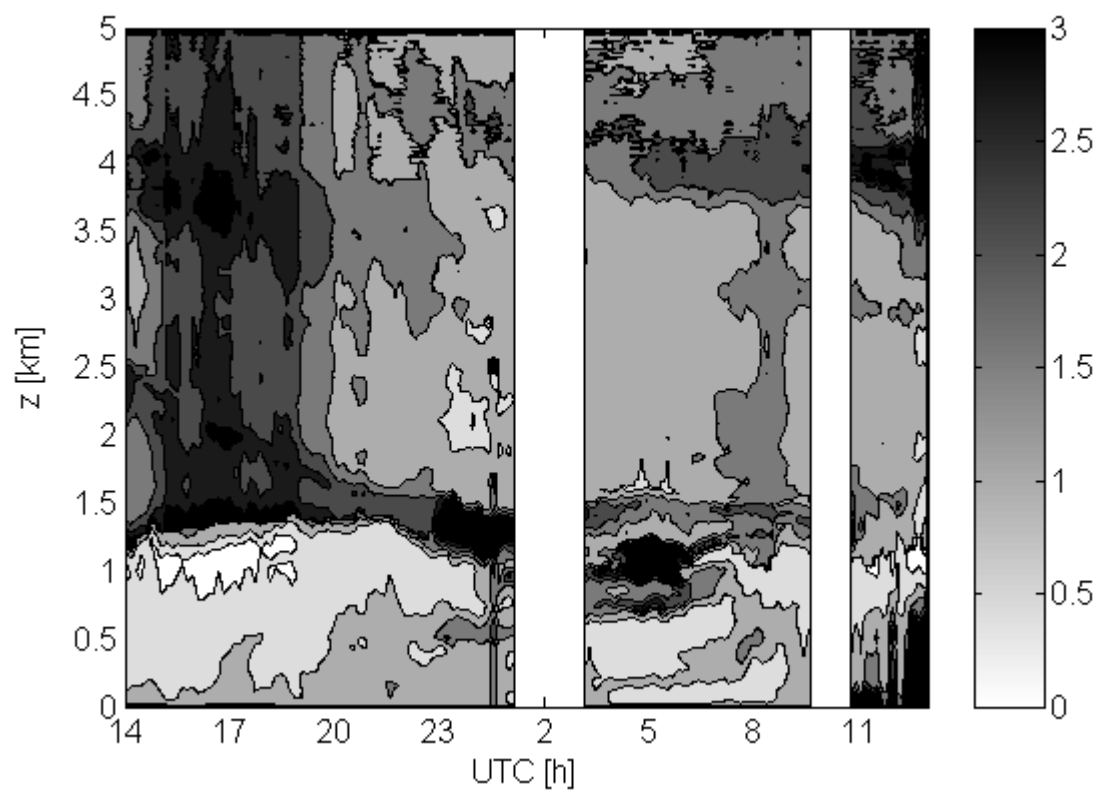

Fig. 10. Temporal evolution of Angstrom exponent vertical profiles calculated on the basis of aerosol extinctions coefficients for 532 and $1064 \mathrm{~nm}$ wavelengths, on the 13-14 April 2005.

\section{ACPD}

6, 12155-12178, 2006

\section{SAWA experiment: properties of mineral dust aerosol}

A. E. Kardas et al.

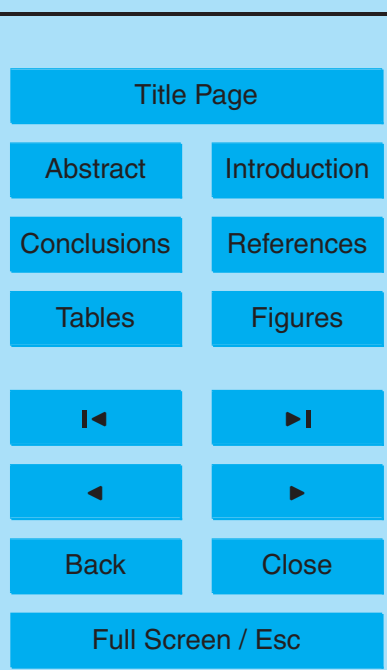

Printer-friendly Version

Interactive Discussion 